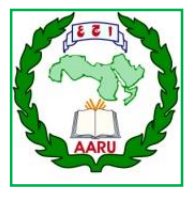

Arab Univ. J. Agric. Sci., Ain Shams Univ., Cairo, Egypt

28(3), 777-795, 2020

Website: http://ajs.journals.ekb.eg

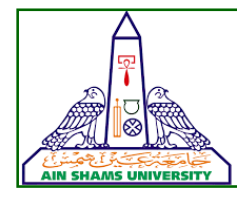

777

\title{
EVALUATION OF LACTOBACILLI PROPERTIES AND THEIR ANTIBACTERIAL SUBSTANCES BY USING SWEET WHEY AS GROWTH MEDIUM AGAINST PATHOGENIC BACTERIA
}

\author{
Radwa E. Noureldein ${ }^{1 *}$, Zaki M.M. ${ }^{1}$, Refaat A.A. ${ }^{1}$ and Abdelsalam A.F. ${ }^{2}$ \\ El-Dougdoug ${ }^{1}$ K.A., Khadiga, A. Abou-Taleb ${ }^{1}$ and Shimaa A. Amin ${ }^{1}$
}

1- Microbiology Dept., Fac. of Agric., Ain Shams Univ., P.O. Box 68, Hadayek Shoubra 11241, Cairo, Egypt

2- Regional Center for Food and Feed, Agric. Research Center

*Corresponding author: chemist.radwa87@yahoo.com

Accepted 7 September, 2020

\section{ABSTRACT}

The increasing demand of consumers who look for natural safe products and associated health risks of chemically treated and refined goods food products led to the introduction of alternative technologies for Preservation and maintenance of dietary freshness. One of such Preservation technology requires the use of Lactobacilli as starter culture for the preservation of food matrixes planned. The present study was designed to evaluate sweet whey low-cost by- product of dairy manufacture as a substrate for the selection of Lactobacilli with proven antibacterial activity to be used as biopreservation for fermented dairy product. Human population has used dairy products, including milk, as a source for Lactic acid bacteria ( $L A B)$. The positive impact of the given bacteria as a diet supplement has been of concern to researchers. The target of this study is to examine Lactobacillus species isolated from dairy products i.e. raw milk alongside cheese, with potential activities. Using the Sweet whey as growth medium for Lactic acid bacteria. Also, tested of antibacterial activities. Sweet whey (sw) proved to be suitable medium alternative to the expensive commercial De Man-Regosa-Sharp medium for the growth and production of antibacterial substances by isolated lactic acid bacteria isolates. Therefore, was used throughout the present work. A number of 32 isolates were obtained from raw cow milk (16 isolates), goat milk (9 isolates) and cottage cheese (7 isolates) using the specific De Man-RegosaSharp medium (MRS) for the isolation of $L A B$, these
\end{abstract}

isolates were identified up to genus as strains of Lactobacillus spp. Among 32 isolates of Lactobacillus spp., there are twenty four isolates antagonized of the all seven tested pathogenic bacteria. The screened Lactobacillus spp. isolates were characterized and selected the best bio agent isolate against pathogens was identified using 16s DNA gene to Lactobacillus brevis. This strain was resistant to $\mathrm{NaCl}(2-6.5 \%)$, produces dioxide carbon $\left(\mathrm{CO}_{2}\right)$ and showed good growth in different temperature $\left(10^{\circ}, 15,45^{\circ} \mathrm{C}\right)$ and fermented of many sugars. As per the outcomes shown herein, the strain in question was thought to be antimicrobial bacterium produced a variety of metabolites, including butyric, formic, lactic, citric, and sorbic acid. The given set of activities adds to microbiological safety by helping control microorganism growth, and inhibiting pathogenic bacteria by using the lower-cost sweet whey. Therefore, more detailed work on isolating and characterizing antibacterial bacteria from the locally produces dairy items, and augmenting their growth could be needed for the creation of biopreservative foods.

Keywords: Lactobacilli, Dairy products, bio preservative, antibacterial. Bioactive gradiants. 16s DNA gene, PCR

\section{INTRODUCTION}

In recent years, live Lactic acid bacteria and non-pathogenic micro-organisms that prove beneficial for health have amassed attention worldwide 
because of their commercial aspects. Lactic acid bacteria are typically deployed when fermented food is being created and are considered safe for veterinary and medical use. Common dairy items that have been in use for several years are the principal source of major antimicrobial bacteria. According to the Agricultural Science and Technology Board, food-borne microbial pathogens contribute to more than 6.5-33 million cases of disease, and about 9,000 deaths annually. The main food items that cause health issues are seafood, dairy, poultry and meat. In majority of the cases, the pathogens at play include issues like Salmonella typhimurium, Listeria monocytogenes, Escherichia coli, Shigella sonnei, Staphylococcus aureus, Bacillus cereus, and Pseudomonas aeruginosa. As well as producing Lactic acid bacteria, which impedes the production of certain microorganisms, allows them to grow within the intestinal tract (Murry et al 2004). Lactic acid bacteria are producing a many of antibacterial metabolites, i.e., organic acids, hydrogen peroxide, acetoin, diacetyl, and bacteriocins. These activities contribute to microbiological health by regulating other microorganism growth and pathogenic bacteria inhibition (Osuntoki and Korie, 2010). Lactobacilli are an important part of our intestinal microflora, and their role in the general state of human health is being studied (Guarner et al 2012). The Lactobacillus spp. genus is one of the major groups of lactic acid bacteria used in the fermentation of food, and is therefore of great economic importance.

The taxonomy of the group Lactobacilli group has undergone essential changes that have created confusion in recent years (Pennacchia et al 2004). A variety of studies have been carried out to define and classify $L A B$. This includes conventional biochemical testing, i.e. carbohydrate fermentation trends through use of commercially sold sits, physiological experiments (Axelsson 1993), and more nuanced molecular biology methods. Lactobacilli were not associated with disease in general and were seen as non-pathogenic parts of the urogenital and intestinal flora (Ali 2012). Lactobacilli has a role to play in the healthy state of the gastrointestinal ecosystem through antagonistic engagement with the under-focus pathogenic bacteria. Lactobacillus species producing antibacterial compounds, including hydrogen peroxide $\left(\mathrm{H}_{2} \mathrm{O}_{2}\right)$, Lactic and other organic acids, and bacteriocins, perform regulatory processes. The goal of this investigation is therefore to use the waste from dairy by-products, including Sweet Whey at the time that the growth medium of lactobacillus spp. To produce bio-preservatives and select the best lactobacillus strain as antibacterial against pathogenic bacteria and optimize their growth by means of static analysis $(\mathrm{pH}, \mathrm{NaCl}$ stress, incubation period, inoculum size and incubation temperature).

\section{MATERIALS AND METHODS}

Samples collection: The different samples, cottage cheese, goat milk and cow milk were collected from the Giza province's local areas. They were transported to the refrigerated laboratory $\left(4^{\circ} \mathrm{C}\right)$, and were immediately analyzed.

Culture sources: Lactobacillus helveticus strain ATCC15009 to compare with LAB isolates and Seven foodborne bacteria and pathogens were kindly collected from the Ain-Shams Univ., Fac. of Agric., Microbiology Research Center (MIRCEN) in Cairo, Egypt. These strains were Bacillus cereus ATCC33018, Staphylococcus aureus ATCC29737, Listeria monocytogenes ATCC19115 (as Gram positive bacteria), Escherichia coli $\mathrm{O}_{157}: \mathrm{H}_{7}$ ATCC25922, Salmonella typhimurium ATCC25566, Pseudomonas aeruginosa ATCC27853, and Shigella sonnei ATCC25931 (as Gram negative bacteria). These strains have been used and activated for the assessment of antibacterial activity of tested lactic acid bacteria.

Isolation of Lactic acid bacteria: Ten $\mathrm{mL}$ of raw milk per sample and $10 \mathrm{~g}$ of cottage cheese have been homogenized with $90 \mathrm{~mL}$ of MRS medium sterile broth. Make sufficient serial dilutions of up to $10-8$ by adding $1 \mathrm{~mL}$ in $9 \mathrm{~mL}$ of the diluent (Lairini et al 2014).

One $\mathrm{mL}$ of every sample dilution was added to sterile Petri Dishes with MRS agar specific medium (De Man et al 1960) and $48-72 \mathrm{~h}$ incubation at $37^{\circ} \mathrm{C}$. Repeated streaking on MRS agar medium purified the selected colonies (Ounine et al 2004). The pure isolates of lactic acid bacteria were stored at $4^{\circ} \mathrm{C}$ and regenerated every four weeks to maintain those (Badis et al 2005).

\section{Identification of Lactic acid bacteria isolated to genus level}

Macroscopic analyses: Macroscopic characters of the cell shape, were examined by light microscope at $1000 \mathrm{X}$ and colonies of lactic acid bacteria is studied by a binocular loupe (Motic) in order to describe their morphology; color, surface, elevation, board, aspect and opacity using a microscope (Motic) linked to a computer and a camera to take pictures with the objective 100 . 

using sweet whey as growth medium against pathogenic bacteria

\section{Physiological and biochemical tests}

Categorization of isolates was based on Gram staining and catalase test. Only the strains Grampositive and catalase negative were retained. Further identification was carried out using the ability to expand to a tolerance of 6.5 percent $\mathrm{NaCl}$ at different temperatures of $10^{\circ} \mathrm{C}, 15^{\circ} \mathrm{C}$ and $45^{\circ} \mathrm{C}$, and Gas production.

Incubation temperatures: The growth test at different temperatures consists of inoculating the young cultures of $\mathrm{LAB}$ isolates in tubes containing the medium MRS broth, then incubated at $10^{\circ} \mathrm{C} 15^{\circ} \mathrm{C}$, and $45^{\circ} \mathrm{C}$ for $72 \mathrm{~h}$. LAB growth indicates how tolerant these temperatures are.

Catalase test: this activity was outlined with the addition of $3 \%(\mathrm{v} / \mathrm{v}) \quad($ sigma) hydrogen peroxide (H2O2) into cultivated colonies, which has been outlined under (Whittenbury, 1964).

Sensitivity to salt: The isolates were tested for tolerance to $6.5 \%(\mathrm{w} / \mathrm{v}) \mathrm{NaCl}$ concentrations in MRS broth medium. The tubes were inoculated with young cultures and then incubated at $37^{\circ} \mathrm{C} / 48 \mathrm{~h}$.

Gas production: The homo or hetero fermentative character of the isolates is studied basing their ability or not ability to produce Carbon dioxide gas $\left(\mathrm{CO}_{2}\right)$. The test was studied using inverted Durham tubes on MRS broth medium (Khedid et al 2009).

Carbohydrate fermentation: Carbohydrate fermentation of isolates by using Api 32 STREP (Bio Mérieux, France) using glucose, sucrose, xylose, sorbitol and lactose according to the manufacturer's instructions (Ismaili et al 2016), and for 48 hours Api STREPS had been incubated at $37^{\circ} \mathrm{C}$.

Preparation of sweet whey medium: As stated, growth of $L A B$ isolates in the sweet whey medium was achieved (Huang et al 2016a). The sweet whey medium was prepared by dissolving the sweet whey powder in distilled water to produce 10 percent of the medium with final total solid content (TS, w/w). This culture medium then was autoclaved at $100^{\circ} \mathrm{C}$ for $20 \mathrm{~min}$ for 3 days before inoculation, respectively. For inoculation, put ( $1 \%$ inoculum size) from the MRS culture and incubation statically at $37^{\circ} \mathrm{C}$ for $48 \mathrm{~h}$.

Preparation of Cell free supernatant (CFS) of isolates: CFS of all the tested isolates was prepared by centrifugation (6000 rpm $/ 30 \mathrm{~min} / 4^{\circ} \mathrm{C}$ ) of actively growing Lactic acid bacteria sub-cultured overnight, followed by aseptic collection of supernatants. The collected CFS was filter-sterilized by passing through a $0.2 \mu \mathrm{m}$ PVDF Whatman sterile Uniflo pore size filter (Nisha and Krishnamoorthy, 2018).

Evaluation of antibacterial activity of isolates by Disc diffusion method: By testing the antimicrobial activity of $L A B$ isolates which are grown on a sweet whey medium against seven pathogenic bacteria and using commercial strain ( $L$. helveticus ATCC15009) for comparing by using the method of disc diffusion as described by (Sandra et al 2012). These assays were conducted in triplicate, the plates were poured with $20 \mathrm{ml}$ of Nutrient Agar, the pathogenic strains were spread over the nutrient agar surface. Before placing the cell-free supernatant (CFS) impregnated paper discs on the plates, the agar plates inoculated with indicator organism were incubated for $1 \mathrm{~h}$. For the screening of antimicrobial activity, 3 sterile paper discs with a diameter of $6 \mathrm{~mm}$ were saturated with $10 \mu \mathrm{l}$ of the filtered supernatant of tested isolate on the surface of the agar plate inoculated by indicator strains. At $37^{\circ} \mathrm{C} / 24$ hours the plates were incubated. Discs dipped in non-inoculated sterile medium acted as control. Inhibition zones is measured in millimeters with calipers (Lleó et al 1998; Mir-hoseini 2004).

Antimicrobial characterization: $\mathrm{LAB}$ isolates and $L$. helveticus were examined for the production of antibacterial substances using the technique of disc diffusion. For different assays the grown culture on sweet whey broth was divided into equal fractions. $10 \mathrm{ml}$ of supernatant was treated with $1 \mathrm{mg} / \mathrm{ml}$ of catalase for hydrogen peroxide assayand incubated for $2 \mathrm{~h}$ at $37^{\circ} \mathrm{C}$. To exclude the antibacterial effect of organic acids, $10 \mathrm{ml}$ of supernatant was adjusted to $\mathrm{pH} 6.5 \pm 0.1$ using $1 \mathrm{NaOH}$. The WDM was then tested for antagonistic activity against indicator bacteria after treatment and neutralization of cell-free supernatants as described above (Ghalfi et al 2006). Inhibition zone was noted after $24 \mathrm{~h}$ of incubation at $37^{\circ} \mathrm{C}$.

Selection of the most active Lactobacillus spp. isolates: Selection of the most active isolates as antimicrobial against of the pathogenic strains by pasteurization at $72^{\circ} \mathrm{C} / 15$ second for the supernatant and testing of antimicrobial activity by disc diffusion then measuring inhibition zone and assayed for residual activity.

Definition selected Lactobacillus isolate by $16 \mathrm{~s}$ DNA gene

DNA Extraction: The supernatant was discarded and the pelt in the saline buffer was suspended. 200 
$\mu \mathrm{l}$ suspended bacteria were placed in $2 \mathrm{ml}$ Ependorf tube and $95 \mu$ of water, $95 \mu$ l of solid tissue buffer (blue) and $10 \mu \mathrm{l}$ of proteinase $\mathrm{K}$ were added. The mixture was incubated for 2 hours at $55^{\circ} \mathrm{C}$, and centrifuged for 1 minute at $12,000 \times \mathrm{g}$. The aqueous supernatant has been transferred to a purified tube $(300 \mu \mathrm{l}) .600 \mathrm{ul}$ Combined Genomic Binding Buffer. The mixture was transferred for 1 minute in a Collection Tube Centrifuge at a Zymo-Spin ${ }^{\mathrm{TM}}$ IIC-XL column $(12,000 \times \mathrm{g})$. With the flow through discard the collection tube400 $\mu$ I DNA Pre-Wash Buffer added to Collection Tube and centrifuged at (12.000 $\mathrm{xg}$ ) for 1 minute. $700 \mu \mathrm{l}$ of $\mathrm{g}$-DNA Wash buffer was added and centrifuged for 1 minute at $(12,000 \mathrm{xg})$. Empty the tube of the set. Add $200 \mu \mathrm{l}$ of g-DNA Wash buffer was added and centrifuged for $1 \mathrm{mi}-$ nute at $(12,000 \mathrm{xg}) .3 \mu \mathrm{l}$ of elution buffer was added and incubated for 5 minutes, then centrifuged for 1 minute at $(12,000 \mathrm{xg})$. PCR reaction setup: $25 \mu \mathrm{L}$ My Taq Red Mix (PCR mix with my base of Taq, PCR buffer and DNA T); $8 \mu \mathrm{L}$ DNA Template; $1 \mu \mathrm{L}(20$ Pico mol) Forward Primers; $1 \mu \mathrm{L}$ (20 Pico mol) Reverse Primers; $15 \mu \mathrm{L}$ Nuclease Free Water. PCR reaction was performed in a thermal cycler condition at 35 cycles of step temperature, each cycle included initial denaturation at $94^{\circ} \mathrm{C}$ for 6 minutes, Denaturation at $94^{\circ} \mathrm{C}$ for $45 \mathrm{~s}$; finishing at $56^{\circ} \mathrm{C}$ for 45 $\mathrm{s}$ Extension at $72^{\circ} \mathrm{C}$ for 1 minute and finishing at $72^{\circ} \mathrm{C}$ for 5 minutes.

The sequencing performed on GATC Company to the PCR product using $A B I 3730 x I$ DNA sequencer using forward and reverse primers. It is only by combining traditional Sanger technology with the new 454 technology that genomes can now be sequenced and analyzed in half the usual project time, with a significant reduction in the number of coatings and lacunae. Additionally, significant cost advantages now make genome sequencing accessible to the research community with the 454 technology.

\section{Analysis of cell-free supernatant (CFS) by HPLC}

Analysis of HPLC selected strain organic acids in cell-free supernatant (CFS), as discerned by (Hu et al 2019). The $\mathrm{pH}$ curve is 3.7 and reaches the end of the log phase at $24 \mathrm{hr}$. The fermented broth was used to separate. The CFS was obtained under cooling by centrifuging $20 \mathrm{~mL}$ of the fermented broth at 6,000 rpm for $30 \mathrm{~min}$. The CFS has been applied to $1 \mathrm{ml}$ of ammonium di hydrogen phosphate buffer, $3 \%$ of methanol, homogenized and Centrifuged at $14,000 \mathrm{~g}$ for $15 \mathrm{~min}$ and 0.22- $\mu \mathrm{m}$ - filter (Nylon; RephiLe Bioscience) was filtered under the cooling process into HPLC amber vials Unfermented MRS broth was tested for controls under similar conditions. The used pure reagents, $L(+)$ tartaric acid and L(-) (malic acid. First, seven common organic acids were identified as standard curves: oxalic acid, tartaric acid, malic acid, lactic acid, citric acid, acetic acid and succinic acid. At the same time it was determined the retaining time of 8 organic acids. The organic acids were detected and quantified using a Photodiode Array Detector (SPD-M20A) Shimadzu Nexera LC system.

A column of C18 (250/4.6 mm I.D., $5 \mu \mathrm{m}$; Teknokroma) was used for chromatographic separation.

The organic acids were eluted using $\mathrm{H} 2 \mathrm{O}$ with $11.5 \%$ ammonium dihydrogen phosphate (solvent A) and methanol (solvent B). Before use, both solvents were filtered and degassed $0.22-\mu \mathrm{m}$. Isocratic elution: solvent A $97 \%$ and solvent B $3 \%$. The flow rate was set at $0.7 \mathrm{ml} / \mathrm{min}$, the temperature set at $25^{\circ} \mathrm{C}$, and the volume was injected at $10 \mu \mathrm{l}$. For UV organic acids were detected at a wavelength of 210 $\mathrm{nm}$. Cell-free supernatant (CFS) analysis by HPLC mode at the Regional Mycology and Biotechnology Centre, Cairo, Egypt.

Statistical analysis: Statistical analysis was done by two designs (Taguchi design and Central composition design (CCD)).

\section{RESULTS AND DISCUSSION}

\section{Isolation of Lactobacillus spp.}

Thirty two of Lactic acid bacteria were isolated from different sources, 7 isolates named, $\mathrm{K} 1$ to $\mathrm{K} 7$ ) isolated from cottage cheese, 9 isolates named, G1 to G9) isolated from goat milk, and 16 isolates. (named, C1 to C16) isolated from cow milk. All isolates were rod shape and Gram positive stain.

\section{Physiological and biochemical characters}

These isolates and Lactobacillus helveticus strain did not produce $\mathrm{CO}_{2}$ from glucose fermentation indicating that they are homo fermentative except isolate $\mathrm{C} 7$ is hetero fermentative due to produce $\mathrm{CO}_{2}$. All isolates and Lactobacillus helveticus strain ferment glucose, lactose, Sucrose, and Xylose, most of them ferment Sorbitol. They grew at $10^{\circ} \mathrm{C}$, but some of them didn't grow at this temperature, they were $(\mathrm{C} 1, \mathrm{C} 2, \mathrm{C} 3, \mathrm{C} 4, \mathrm{C} 5$, and $\mathrm{C} 6)$ and the isolates weren't grown at $15^{\circ} \mathrm{C}(\mathrm{C} 1, \mathrm{C} 3, \mathrm{C} 4$, and $\mathrm{C} 5)$, but all isolates were grown at $45^{\circ} \mathrm{C}$. All isolates grew at $2-4 \% \mathrm{Nacl}$, while some isolates grew at $6.5 \%$ $\mathrm{Nacl}$ and some of them didn't grow like (C1, C3, C4, and (6). Using these characteristics all isolates 

using sweet whey as growth medium against pathogenic bacteria

were identified as members of the genus Lactobacillus spp. according to Bergey's Manual of determinative Bacteriology (Table 1).

\section{Antibacterial activity}

Evaluation of 32 Lactobacillus spp. Isolates and Lactobacillus helveticus strain against 7 pathogens on broth sweet whey medium by disc diffusion assay by (Sandra et al 2012) was estimated. They were produced with differed strong inhibition zones against 7 pathogens. It was found Lactobacillus helveticus strain and 28 out of 32 isolates except (K2, G5, G6, G7) were active as antibacterial against Bacillus cereus, Lactobacillus helveticus strain and 29 out of 32 isolates except (G5, G6, G7) were active as antibacterial against Staphylococcus aureus, Lactobacillus helveticus strain and 27 out of 32 isolates except (K1,K2, K7, G5, G6 ) were active as antibacterial against Listeria monocytogenes, Lactobacillus helveticus strain and 31 out of 32 isolates except only (G6) were active as anti E. coli, Lactobacillus helveticus strain and 28 out of 32 isolates except (G5, G6, G7, C13) were active as antibacterial against Pseudomonas aeruginosa, Lactobacillus helveticus strain and all 32 isolates were active as antibacterial against Shigella sonnei and Lactobacillus helveticus strain and 29 out of 32 isolates except (G5, G6, G7) were active as antibacterial against Salmonella typhimurium . Antagonistic activity of $L A B$ isolates against all 7 pathogenic bacteria, with different efficiency are presented in (Table 2).

\section{Characterization of antimicrobial substances}

Total acidity activity: The antibacterial activity of 24 selected Lactobacillus spp. Isolates and Lactobacillus helveticus strain before acid neutralized was appeared because of its organic acid production but disappeared after acid neutralized. On the other hand, not produced bactriocin and $\mathrm{H}_{2} \mathrm{O}_{2}$, where after eliminated effect of $\mathrm{H}_{2} \mathrm{O}_{2}$.

\section{Selection of the most active isolates}

After the pasteurization, only 11 isolates from 24 $(11 / 24)$ were not sensitivity for the pasteurization, but only 5 isolates antagonized the 7 pathogens showing- highest residual activity after pasteurization. There strains were $\mathrm{K} 5$ and $\mathrm{K} 6$ from Cottage cheese, C3 and C7 from cow milk and G9 from goat milk (Table 3). Of this $\mathrm{C} 7$ isolate showed the relatively highest residual activity against Staphylococcus aureus (87.8\%), E. coli (72.2\%), Pseudomonas aeruginosa (92.6\%) and Shigella sonnei $(91.9 \%)$ as compared with the remainder four isolates.

\section{Molecular characters of Lactobacillus spp.}

Total DNA extraction: Total DNA was extracted from Lactobacillus spp. Gel electrophoresis and a UV spectrophotometer verified the quality and quantity of the filtered DNA. The Lactobacillus spp. concentration was $75 \mu \mathrm{g} / 0.5 \mathrm{gm}$ and the purity of the total DNA measured for Lactobacillus spp. by an A260/280 absorbance ratio (1.6) suggesting high yield and purity of the extracted DNAs.

16s DNA Gene Amplification: Lactobacillus spp. / 16s The DNA gene was amplified from Lactobacillus spp. extracted DNAs. Use of the resulting PCR technique Lactobacillus spp. / DNA mixed directly with the PCR reaction mixture, taq DNA polymerase and (sense and antisense) primers. Electrophoresis study of the amplified 16s DNA gene corresponding to the $16 \mathrm{~s}$ DNA gene in the $\mathrm{C}$-terminal region. The size of the PCR product amplified from LactobacilIus spp. /DNA was estimated by comparing its electrophoretic mobility with those of standard DNA marker as shown in (Fig. 2). The amplified cDNA was in the expected size calculated (1100 bp) from the positions of sense primers.

\section{Nucleotide sequence analysis}

The PCR-amplified partial nucleotide sequence fragmented the 16s DNA gene of Lactobacillus spp. isolate in the C-terminal region. Determining the relationship with other recommended Lactobacillus spp. strains registered with GenBank. The 16s DNA gene sequence was performed using PCR produced when the specific (downstream) primers of Lactobacillus spp. for 16s RNA gene were used. Nucleotides were found to be 1049 bp corresponding to the C-terminal region of 16s RNA gene (Fig. 3).

\section{Bioinformatics analysis of molecular data}

The partial nucleotide sequence of 16s RNA gene was aligned with 21 Lactobacillus isolates with (Table 4). The partial sequence was multiplealigned with the claustral W program with minor manual adjustments (Fig. 4). The distances of nucleotides between isolates ranged from 0.004 to 0.064 (Table 4). The lower values for the Lactobacillus paucivorans isolate pairs (NR 1169431 ) were recorded. For 20 isolates, the greater nucleotide distance values were reported. A phylogenetic tree of 16 s RNA gene revealed $98.43 \%$ of similarity to Lactobacillus brevis (Accession no NR_116238 1) (Fig. 4). 
Table 1. Physiological and biochemical characters: of Isolated Lactobacillus spp.

\begin{tabular}{|c|c|c|c|c|c|c|c|c|c|c|c|c|c|}
\hline \multirow{2}{*}{ Source } & \multirow{2}{*}{$\begin{array}{c}\text { Isolate } \\
\text { no. }\end{array}$} & \multicolumn{5}{|c|}{ Fermentation of sugars } & \multirow{2}{*}{$\begin{array}{l}\text { Gas } \\
\mathrm{CO}_{2} \\
\end{array}$} & \multicolumn{3}{|c|}{ temperature } & \multicolumn{3}{|c|}{$\mathrm{NaCl}$} \\
\hline & & $\mathbf{G}$ & Lac & $\mathbf{X y}$ & Su & So & & $10^{\circ} \mathrm{C}$ & $15^{\circ} \mathrm{C}$ & $45^{\circ} \mathrm{C}$ & $2 \%$ & $4 \%$ & $6.5 \%$ \\
\hline \multirow{11}{*}{ Cottage cheese } & K1 & + & + & + & + & + & - & + & + & + & + & + & + \\
\hline & K2 & + & + & + & + & + & - & + & + & + & + & + & + \\
\hline & K3 & + & + & + & + & + & - & + & + & + & + & + & + \\
\hline & K4 & + & + & + & + & + & - & + & + & + & + & + & + \\
\hline & K5 & + & + & + & + & + & - & + & + & + & + & + & + \\
\hline & $\mathrm{K} 6$ & + & + & + & + & + & - & + & + & + & + & + & + \\
\hline & K7 & + & + & + & + & + & - & + & + & + & + & + & + \\
\hline & G1 & + & + & + & + & + & - & + & + & + & + & + & + \\
\hline & G2 & + & + & + & + & + & - & + & + & + & + & + & + \\
\hline & G3 & + & + & + & + & + & - & + & + & + & + & + & + \\
\hline & G4 & + & + & + & + & + & - & + & + & + & + & + & + \\
\hline \multirow[t]{8}{*}{ Goat Milk } & G5 & + & + & + & + & + & - & + & + & + & + & + & + \\
\hline & G6 & + & + & + & + & + & - & + & + & + & + & + & + \\
\hline & G7 & + & + & + & + & + & - & + & + & + & + & + & + \\
\hline & G8 & + & + & + & + & + & - & + & + & + & + & + & + \\
\hline & G9 & + & + & + & + & + & - & + & + & + & + & + & + \\
\hline & C1 & + & + & + & + & + & - & - & - & + & + & + & - \\
\hline & $\mathrm{C} 2$ & + & + & + & + & + & - & - & + & + & + & + & + \\
\hline & C3 & + & + & + & + & - & - & - & - & + & + & + & - \\
\hline \multirow[t]{13}{*}{ Cow Milk } & C4 & + & + & + & + & + & - & - & - & + & + & + & - \\
\hline & C5 & + & + & + & + & + & - & - & - & + & + & + & + \\
\hline & C6 & + & + & + & + & + & - & - & + & + & + & + & - \\
\hline & $\mathrm{C7}$ & + & + & + & + & + & + & + & + & + & + & + & + \\
\hline & C8 & + & + & + & + & + & - & + & + & + & + & + & + \\
\hline & C9 & + & + & + & + & + & - & + & + & + & + & + & + \\
\hline & C10 & + & + & + & + & + & - & + & + & + & + & + & + \\
\hline & C11 & + & + & + & + & + & - & + & + & + & + & + & + \\
\hline & C12 & + & + & + & + & + & - & + & + & + & + & + & + \\
\hline & C13 & + & + & + & + & + & - & + & + & + & + & + & + \\
\hline & C14 & + & + & + & + & + & - & + & + & + & + & + & + \\
\hline & C15 & + & + & + & + & + & - & + & + & + & + & + & + \\
\hline & C16 & + & + & + & + & + & - & + & + & + & + & + & + \\
\hline L.helveticus & & + & + & + & + & + & - & + & + & + & + & + & + \\
\hline
\end{tabular}

(G): Glucose (Lac): Lactose (Xy): Xylose (Su): Sucrose (So): Sorbitol 

using sweet whey as growth medium against pathogenic bacteria

Table 2. The diameter $(\mathrm{mm})$ of inhibition zone of isolates against tested pathogens

\begin{tabular}{|c|c|c|c|c|c|c|c|c|c|}
\hline \multirow[b]{4}{*}{ Source } & \multirow[b]{4}{*}{ 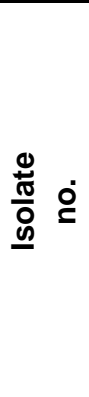 } & \multicolumn{7}{|c|}{ Inhibition zone(mm) } & \multirow{4}{*}{ 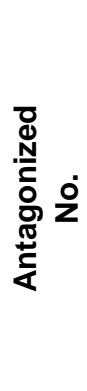 } \\
\hline & & \multicolumn{7}{|c|}{ Pathogenic organisms } & \\
\hline & & \multicolumn{3}{|c|}{$\mathbf{G}^{+}$} & \multicolumn{4}{|c|}{ G- } & \\
\hline & & 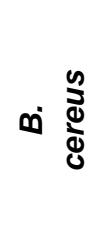 & 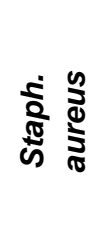 & 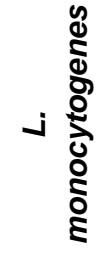 & $\begin{array}{l}\text { 亏े } \\
\text { ư }\end{array}$ & ৫ి & 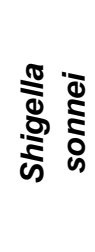 & vi & \\
\hline \multirow{7}{*}{$\begin{array}{l}\text { Cottage } \\
\text { cheese }\end{array}$} & K1 & 9.00 & 8.00 & 0.00 & 20.00 & 12.00 & 19.00 & 8.00 & 6 \\
\hline & $\mathrm{K} 2$ & 0.00 & 9.60 & 0.00 & 22.00 & 12.00 & 21.00 & 14.00 & 5 \\
\hline & K3 & 12.80 & 10.30 & 13.00 & 20.00 & 16.00 & 22.00 & 14.00 & 7 \\
\hline & K4 & 13.50 & 9.00 & 21.00 & 23.00 & 13.00 & 16.00 & 11.00 & 7 \\
\hline & K5 & 15.00 & 13.00 & 16.30 & 25.00 & 12.60 & 27.00 & 19.00 & 7 \\
\hline & K6 & 17.00 & 12.60 & 19.60 & 26.00 & 16.00 & 28.00 & 15.60 & 7 \\
\hline & K7 & 13.00 & 10.50 & 0.00 & 24.00 & 18.00 & 26.00 & 14.00 & 6 \\
\hline \multirow{9}{*}{$\begin{array}{l}\text { Goat } \\
\text { milk }\end{array}$} & G1 & 11.80 & 8.50 & 19.00 & 18.00 & 10.00 & 15.00 & 9.00 & 7 \\
\hline & G2 & 8.60 & 8.00 & 8.00 & 16.00 & 9.00 & 17.00 & 7.00 & 7 \\
\hline & G3 & 13.60 & 9.60 & 13.10 & 21.00 & 16.00 & 21.00 & 13.50 & 7 \\
\hline & G4 & 13.80 & 9.60 & 11.60 & 24.00 & 10.00 & 17.00 & 11.00 & 7 \\
\hline & G5 & 0.00 & 0.00 & 0.00 & 15.00 & 0.00 & 14.00 & 0.00 & 2 \\
\hline & G6 & 0.00 & 0.00 & 0.00 & 0.00 & 0.00 & 13.00 & 0.00 & 1 \\
\hline & G7 & 0.00 & 0.00 & 10.00 & 20.00 & 0.00 & 15.00 & 0.00 & 3 \\
\hline & G8 & 13.00 & 11.00 & 18.00 & 23.00 & 13.60 & 26.00 & 15.00 & 7 \\
\hline & G9 & 13.80 & 14.60 & 14.80 & 25.00 & 12.80 & 24.00 & 11.00 & 7 \\
\hline \multirow{16}{*}{ Cow milk } & C1 & 18.60 & 12.00 & 15.60 & 30.00 & 15.00 & 28.00 & 15.60 & 7 \\
\hline & $\mathrm{C} 2$ & 16.60 & 11.00 & 14.60 & 18.00 & 16.00 & 21.00 & 13.00 & 7 \\
\hline & C3 & 13.60 & 11.00 & 18.50 & 13.00 & 17.00 & 18.00 & 11.50 & 7 \\
\hline & C4 & 12.00 & 9.00 & 16.30 & 20.00 & 11.00 & 15.00 & 14.00 & 7 \\
\hline & C5 & 13.00 & 11.00 & 17.60 & 20.00 & 10.00 & 26.00 & 13.60 & 7 \\
\hline & C6 & 12.60 & 10.00 & 13.30 & 19.00 & 11.60 & 22.00 & 16.00 & 7 \\
\hline & C7 & 17.80 & 14.80 & 19.50 & 23.00 & 13.50 & 21.00 & 14.00 & 7 \\
\hline & C8 & 12.00 & 13.00 & 13.60 & 19.00 & 12.00 & 17.00 & 9.00 & 7 \\
\hline & C9 & 17.00 & 11.00 & 21.60 & 22.00 & 10.60 & 20.00 & 19.00 & 7 \\
\hline & C10 & 9.00 & 8.60 & 11.60 & 15.00 & 0.00 & 16.00 & 7.60 & 6 \\
\hline & C11 & 10.00 & 9.00 & 13.60 & 17.00 & 12.00 & 17.00 & 10.00 & 7 \\
\hline & C12 & 10.00 & 9.00 & 16.00 & 25.00 & 9.00 & 22.00 & 14.00 & 7 \\
\hline & C13 & 8.60 & 9.00 & 13.00 & 20.00 & 0.00 & 14.00 & 11.00 & 6 \\
\hline & C14 & 8.00 & 10.00 & 15.00 & 14.00 & 14.00 & 17.00 & 8.00 & 7 \\
\hline & C15 & 16.00 & 14.60 & 16.50 & 28.00 & 11.50 & 24.00 & 14.00 & 7 \\
\hline & C16 & 10.00 & 11.00 & 15.60 & 29.00 & 12.00 & 26.00 & 16.00 & 7 \\
\hline \multicolumn{2}{|c|}{ L. helveticus } & 10.00 & 13.00 & 15.00 & 14.00 & 14.00 & 17.00 & 10.00 & 7 \\
\hline
\end{tabular}

$0.00=$ No effect, $<7$ = Low strong (Resistance), 7-10 mm = strong (Intermediated Resistance), $>10 \mathrm{~mm}$ inhibition zone = Very strong (Very Sensitivity) 


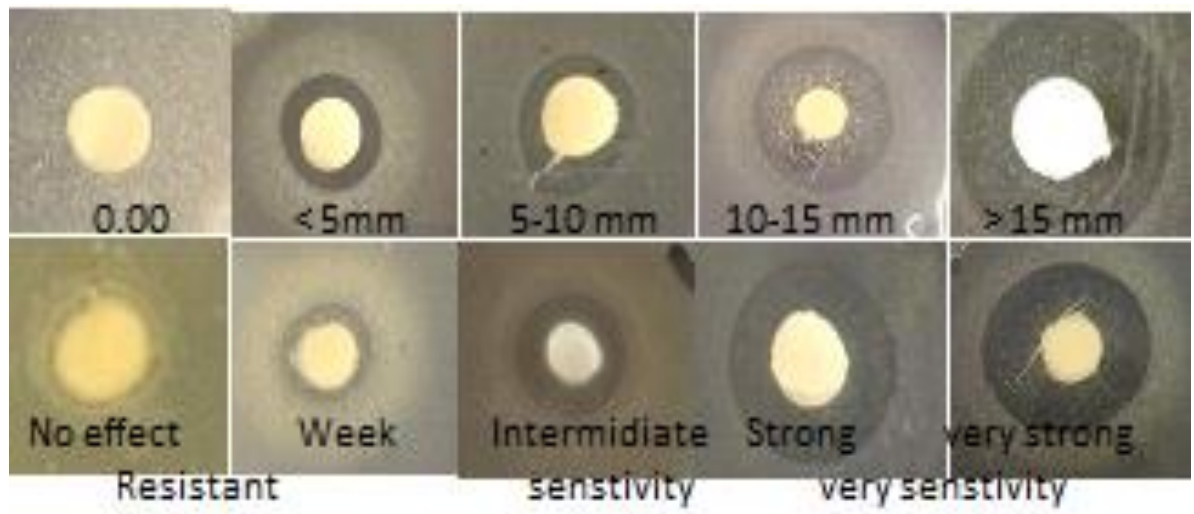

Fig. 1. Disk diffusion plate showing degree and type the antibacterial activity of Lactobacillus isolates using inhibition zone $(\mathrm{mm})$.

Table 3. Residual activity (\%) of Lactobacillus spp. isolates after pasteurization $\left(72^{\circ} \mathrm{C} / 15 \mathrm{~min}\right)$ antagonized seven pathogens

\begin{tabular}{|c|c|c|c|c|c|c|c|}
\hline \multirow{3}{*}{ Isolate No. } & \multicolumn{7}{|c|}{ Residual activity (\%) } \\
\hline & \multicolumn{7}{|c|}{ Pathogenic organisms } \\
\hline & $\begin{array}{c}\text { B. } \\
\text { cereus }\end{array}$ & $\begin{array}{l}\text { Staph. } \\
\text { aureus }\end{array}$ & \begin{tabular}{|c|}
$L$. \\
monocytogenes \\
\end{tabular} & E.coli & $\begin{array}{c}\text { Ps. } \\
\text { aeruginosa } \\
\end{array}$ & $\begin{array}{c}\text { Shigella } \\
\text { sonnei }\end{array}$ & $\begin{array}{c}\text { S. } \\
\text { typhimurium }\end{array}$ \\
\hline K3 & 98.43 & 0.00 & 89.20 & 50.00 & 43.75 & 43.63 & 80.71 \\
\hline K4 & 0.00 & 0.00 & 85.71 & 56.52 & 0.00 & 0.00 & 0.00 \\
\hline K5 & 95.33 & 84.62 & 93.90 & 40.00 & 57.93 & 34.44 & 57.89 \\
\hline K6 & 95.88 & 79.36 & 98.50 & 70.40 & 68.75 & 34.64 & 67.95 \\
\hline G1 & 0.00 & 0.00 & 78.94 & 55.55 & 0.00 & 0.00 & 0.00 \\
\hline G2 & 0.00 & 0.00 & 75.00 & 0.00 & 0.00 & 0.00 & 0.00 \\
\hline G3 & 0.00 & 72.92 & 96.20 & 74.30 & 0.00 & 0.00 & 0.00 \\
\hline G4 & 76.81 & 0.00 & 97.41 & 25.00 & 87.00 & 0.00 & 0.00 \\
\hline G8 & 0.00 & 0.00 & 0.00 & 53.50 & 71.32 & 0.00 & 0.00 \\
\hline G9 & 84.05 & 75.34 & 96.60 & 57.20 & 82.81 & 47.08 & 100.00 \\
\hline $\mathrm{C} 1$ & 60.75 & 0.00 & 96.20 & 53.30 & 0.00 & 36.79 & 62.18 \\
\hline $\mathrm{C} 2$ & 74.09 & 96.36 & 75.30 & 35.00 & 0.00 & 44.29 & 76.92 \\
\hline C3 & 88.23 & 50.90 & 81.00 & 100.00 & 52.94 & 55.56 & 98.26 \\
\hline C4 & 0.00 & 0.00 & 58.90 & 48.00 & 96.36 & 76.84 & 78.60 \\
\hline C5 & 84.61 & 0.00 & 73.90 & 48.00 & 0.00 & 40.77 & 68.38 \\
\hline C6 & 97.62 & 0.00 & 100.00 & 97.90 & 62.93 & 61.81 & 62.50 \\
\hline C7 & 89.89 & 87.80 & 90.30 & 72.20 & 92.60 & 91.90 & 97.90 \\
\hline C8 & 75.00 & 0.00 & 100.00 & 48.94 & 52.50 & 0.00 & 0.00 \\
\hline C9 & 38.82 & 0.00 & 76.90 & 51.40 & 52.83 & 41.5 & 48.95 \\
\hline C11 & 0.00 & 0.00 & 95.60 & 82.35 & 0.00 & 0.00 & 0.00 \\
\hline C12 & 90.00 & 0.00 & 53.20 & 41.20 & 0.00 & 25.90 & 0.00 \\
\hline C14 & 0.00 & 0.00 & 84.00 & 59.30 & 0.00 & 49.00 & 0.00 \\
\hline C15 & 56.25 & 0.00 & 97.00 & 60.70 & 0.00 & 22.08 & 0.00 \\
\hline C16 & 83.30 & 0.00 & 66.00 & 66.60 & 69.42 & 34.62 & 56.25 \\
\hline L. helveticus & 0.00 & 0.00 & 84.00 & 59.30 & 0.00 & 49.00 & 0.00 \\
\hline
\end{tabular}


Evaluation of Lactobacilli properties and their antibacterial substances by using sweet whey as growth medium against pathogenic bacteria

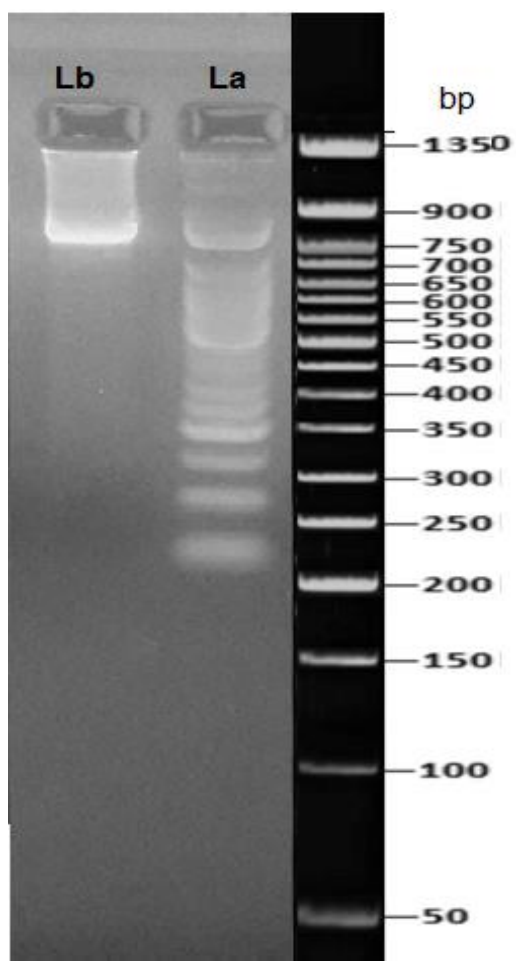

Fig. 2. 1\% Agarose gel electrophoresis showing (Lb) Lactobacillus spp. / DNA - PCR product amplified from total DNA extracted from Lactobacillus spp. using sense and antisense primers. (L) DNA ladder high molecular weight.

(Bf) >200217-029_M04_A4-group10_BF-group10.ab1 1049

TGCCCCAAGCTACTGCCTACTACATGCAAGTGCGACGAGCTTCCGTTGAATGACGTGCTTGCACTGA TTTCAACAATGAAGCGAGTGGCGAACTGGTGATAACACGTGGGAAATCTGCCCAGAAGCAGGGGATA ACACTTGGAAACAGGTGCTAATACCGTATAACAACAAAATCCGCATGGATTTTTGTTTGAAAGGTGGCT TCGGCTATCACTTCTGGATGATCCCGCGGCGTATTAGTTAGTTGGTGAGGTAAAGGCCCACCAAGAC GATGATACGTAGCCGACCTGAGAGGGTAATCGGCCACATTGGGACTGAGACACGGCCCAAACTCCTA CGGGAGGCAGCAGTAGGGAATCTTCCACAATGGACGAAAGTCTGATGGAGCAATGCCGCGTGAGTG AAGAAGGGTTTCGGCTCGTAAAACTCTGTTGTTAAAGAAGAACACCTTTGAGAGTAACTGTTCAAGGG TTGACGGTATTTAACCAGAAAGCCACGGCTAACTACGTGCCAGCAGCCGCGGTAATACGTAGGTGGC AAGCGTTGTCCGGATTTATTGGGCGTAAAGCGAGCGCAGGCGGTTTTTTAAGTCTGATGTGAAAGCC TTCGGCTTAACCGGAGAAGTGCATCGGAAACTGGGAGACTTGAGTGCAGAAGAGGACAGTGGAACTC CATGTGTAGCGGTGGAATGCGTAGATAATGGAAGAACACCAGTGGCGAAGGCGGCTGTCTAGTCTG TAACTGACGCTGAGGCTCGAAAAGCATGGGTAGCGAACAGGATTAGATACCCTGGTAGTCCATGCCC GTAAACGATGAGTGCTAAGTGGTTGGAAGGGTTTCCGCCCTTCAGTGCTGCAGCTAACGCATTTAAG CACTCCCGCCTGGGGGAGTACGAACCGCCAAGGGTTGAAAACTCCACAGGAAATTGACGGGGGGGC CCGCCACAAACCGGTGGAAGCATGTGGGTTTAATTTCAAAAGCTACGCCGAAGAAACCTTTACCCAG GGTCTTGGACATTTTTTTTTGCCCTTTTTTTTTGAAAATTTTGCC

Fig. 3. Lactobacillus brevis ATCC 14869 = DSM 2005416 S ribosomal RNA, partial sequence 


\section{Radwa Noureldein, Zaki; Refaat and Abdelsalam; El-Dougdoug;} Khadiga Abou-Taleb and Shimaa Amin

Table 4. Accession no of Lactobacillus spp. isolates recorded in gene bank was aligned with selected Lactobacillus isolate

\section{Descriptio}

Lactobacillus brevis ATCC $14869=$ DSM 2005416 S ribosomal RNA. partial sequence

Lactobacillus brevis strain ATCC 1486916 S ribosomal RNA. partial sequence

Lactobacillus yonginensis strain THK-V8 16 S ribosomal RNA, partial sequence

Lactobacillus cerevisiae strain TUM BP 140423000-2250 16S ribosomal RNA, partial sequence

Lactobacillus koreensis JCM 16448 strain DCY50 16 S ribosomal RNA, partial sequence

Lactobacillus parabrevis strain LMG 11984 16S ribosomal RNA.partial sequence

Lactobacillus hammesii strain type strain: TMW 1.123616 S ribosomal RNA. partial sequence

Lactobacillus senmaizukei DSM $21775=$ NBRC 10385316 S ribosomal RNA, partial sequence

Lactobacillus senmaizukei DSM $21775=$ NBRC 103853 strain L13 16S ribosomal RNA.partial sequence

Lactobacillus spicheri strain LTH 5753 16S ribosomal RNA, partial sequence

Lactobacillus zymae strain R-18615 16 S ribosomal RNA_partial sequence

Lactobacillus acidifarinae strain R-19065 16S ribosomal RNA,partial sequence

Lactobacillus namurensis strain R-27965 16 S ribosomal RNA.partial sequence

Lactobacillus paucivorans strain TMW 1.1424 16S ribosomal RNA, partial sequence

Lactobacillus odoratitofui DSM $19909=$ JCM 15043 strain YIT 1130416 r ribosomal RNA, partial sequence

Lactobacillus mixtipabuli strain IWT30 16S ribosomal RNA, partial sequence

Lactobacillus kimchicus JCM 15530 strain DCY51 16S ribosomal RNA, partial sequence

Lactobacillus similis DSM 23365 = JCM 2765 16S ribosomal RNA.partial sequence

Lactobacillus silagincola strain IWT5 16S ribosomal RNA, partial sequence

Lactobacillus paracollinoides strain JCM 1196916 S ribosomal RNA, partial sequence

Lactobacillus paracollinoides strain JCM 1196916 S ribosomal RNA.partial sequence

\begin{tabular}{|c|c|c|c|c|c|}
\hline $\begin{array}{l}\text { Max } \\
\text { Score }\end{array}$ & $\begin{array}{l}\text { Total } \\
\text { Score }\end{array}$ & $\begin{array}{l}\text { Query } \\
\text { Cover }\end{array}$ & $\begin{array}{c}E \\
\text { value }\end{array}$ & $\begin{array}{l}\text { Per. } \\
\text { Ident }\end{array}$ & Accession \\
\hline 1559 & 1559 & $100 \%$ & 0.0 & $98.43 \%$ & 6238.1 \\
\hline 1543 & 1543 & $100 \%$ & 0.0 & $97.98 \%$ & NR 044704.2 \\
\hline 1487 & 1487 & $100 \%$ & 0.0 & $96.98 \%$ & NR 109452.1 \\
\hline 1467 & 1467 & $100 \%$ & 0.0 & $96.53 \%$ & NR 158030.1 \\
\hline 1465 & 1465 & $100 \%$ & 0.0 & $96.53 \%$ & NR 116854.1 \\
\hline 1450 & 1450 & $100 \%$ & 0.0 & $96.19 \%$ & NR 042456.1 \\
\hline 1443 & 1443 & $100 \%$ & 0.0 & $96.08 \%$ & NR 042243.1 \\
\hline 1437 & 1437 & $100 \%$ & 0.0 & $95.86 \%$ & NR 114251.1 \\
\hline 1426 & 1426 & $100 \%$ & 0.0 & $95.74 \%$ & NR 041584.1 \\
\hline 1417 & 1417 & $99 \%$ & 0.0 & $95.73 \%$ & NR 025579.1 \\
\hline 1373 & 1373 & $99 \%$ & 0.0 & $94.83 \%$ & NR 042241.1 \\
\hline 1371 & 1371 & $99 \%$ & 0.0 & $94.71 \%$ & NR 042242 \\
\hline 1339 & 1339 & $99 \%$ & 0.0 & $94.15 \%$ & $\underline{\text { NR } 042514.1}$ \\
\hline 1334 & 1334 & $99 \%$ & 0.0 & $93.96 \%$ & NR 116943.1 \\
\hline 1330 & 1330 & $99 \%$ & 0.0 & $93.93 \%$ & NR 112739.1 \\
\hline 1308 & 1308 & $99 \%$ & 0.0 & $93.48 \%$ & NR 135897.1 \\
\hline 1308 & 1308 & $99 \%$ & 0.0 & $93.49 \%$ & $\underline{\text { NR }} 116411.1$ \\
\hline 1306 & 1306 & $99 \%$ & 0.0 & $93.48 \%$ & NR 112645.1 \\
\hline 1303 & 1303 & $99 \%$ & 0.0 & $93.37 \%$ & NR 158059.1 \\
\hline 1301 & 1301 & $99 \%$ & 0.0 & $93.36 \%$ & $\underline{\text { NR } 112846.1}$ \\
\hline 1301 & 1301 & $99 \%$ & 0.0 & $93.36 \%$ & $\underline{\text { NR } 112756}$ \\
\hline
\end{tabular}

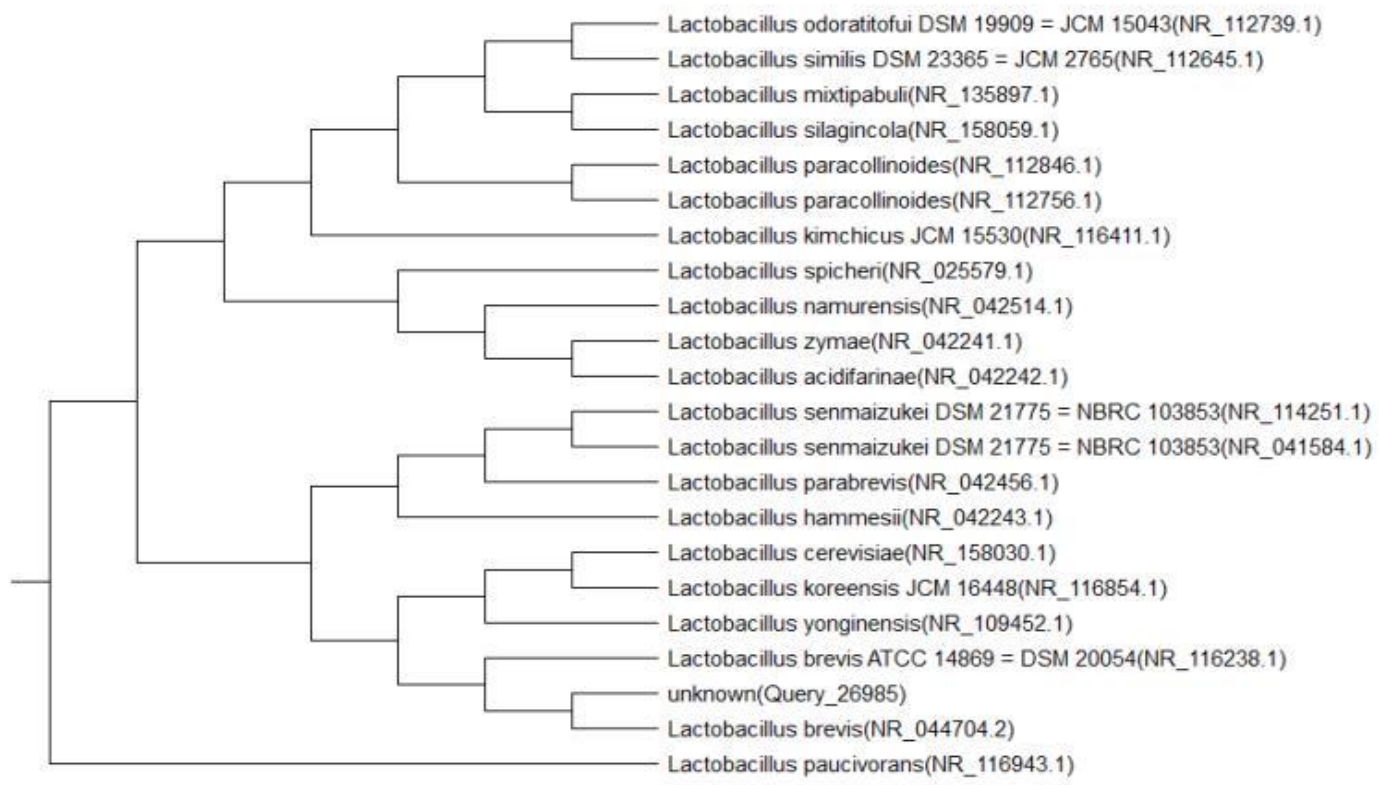

Fig. 4. A phylogenetic tree of Lactobacillus isolate revealed $98.43 \%$ a moderate degree of similarity to Lactobacillus brevis ATCC 14869 isolate (Accession no. NR_116238 1) 

using sweet whey as growth medium against pathogenic bacteria

\section{An antibacterial substratum analysis in fermen- tation broth Lactobacillus brevis (C7)}

It was a genus of nonspore, Gram-positive bacteria whose most common feature is the fermentation of sugars into organic acids. The decrease in $\mathrm{pH}$ can seriously inhibit other bacteria's production. In addition, several other studies have found that $\mathrm{H}_{2} \mathrm{O}_{2}$ produced during the metabolic process can inhibit bacteria (Charlier et al 2009 and $\mathrm{Hu}$ et al 2019). On the other hand, some lactic acid bacteria can produce pathogen-inhibiting bacteriocins and bacteriocin-like compounds (Zhao et al 2016). They can produce a variety of organic acids, mainly Probiotic acid, lactic acid, Citric acid, formic acid, sorbic acid and butyric acid 15.23, 12.365.22, 4.96, 3.12 and $1.25 \mathrm{mg} / \mathrm{mL}$ respectively in the fermentation broth of Lactobacillus brevis (C7) (Table 5 and Fig. 5) . The organic acids that have an antimicrobial behavior are the acetic acids and lactic acids in the metabolite products of Lactobacillus brevis (C7) (Zalán et al 2010). Additionally, other common organic acids like citric acid may also possess antibacterial activity. The lactic acid, citric acid, was chosen for determination in our study. According to Lactobacillus brevis (C7) $\mathrm{pH}$ curve, the $\mathrm{pH}$ of the fermentation broth stabilizes after 24 hours at 3.80 (Hu et al 2019), five types of organic acids were found in the three strains fermentation broth by HPLC analysis. Organic acid extracted from L. Plantarum strains (P1, S11, and M7) were mainly lactic acid and were the lowest in L. S11 $(26.4 \mathrm{~g} / \mathrm{L})$ plantarum Against L. Plantarum L. and S11. M7, L. plantarum, the highest concentrations of acetic (3.3 $\mathrm{g} / \mathrm{L})$ and lactic acid (2.6 g / L) were detected in plantarum P1. Beyond that, all fermentation broths also detected a tiny bit of tartaric and malic acid. The lactic acid content is the highest compared with other organic acids, and proves to be the key ingredient behind the fall in the $\mathrm{pH}$ level of the broth. This reduction has an impact that is inhibitory in nature and directly affects the pathogenic bacteria, effectively stunting its growth.

\section{Optimization of growth of selected strain}

Screening of the most significant cell dry weight parameters by using Taguchi design

A total of 5 factors including $(\mathrm{NaCl}$ concentration, $\mathrm{pH}$, inoculum size, temperature and incubation period) with four rates were chosen to conduct this optimization phase (which will provide an appropriate error estimate) studied in $16(n+1)$ Lactobacillus strain C7 experiments. Data in (Table 6), showed that the biomass production was ranged from 0.87 to $0.98 \mathrm{~g} / \mathrm{l}$ due to the influence of interactions between variables. Maximum cell dry weight $(0.98 \mathrm{~g} / \mathrm{l})$ was achieved at run number 15 , followed by run $11(0.97 \mathrm{~g} / \mathrm{l}$ of cell dry weight). The run 15 was the best run which was the optimum conditions for cell dry weight represented $4 \mathrm{~g} \mathrm{Nacl} / 100 \mathrm{ml}$, adjusted $\mathrm{pH}$ to 7.5 and inoculated with $5 \%$ of the Lactobacillus brevis (C7) then incubated at $25^{\circ} \mathrm{C}$ for 72 hours. Results also indicated that the lowest cell dry weight was observed in run number 3 being $0.87 \mathrm{~g} / \mathrm{l}$.

Analysis of variance (ANOVA) through the Fisher test has been deployed to examine the impact of variables that are independent when it comes to the response. Substantial results were outlined where the $\mathrm{p}$-value stood at $<0.05$. Adjusted $\mathrm{R} 2$ and multiple determination coefficient $(\mathrm{R})$ were put to use to check on quality so that the fitness of the second order poly nomial equation could be evaluated. Adeq Precision " measures the signal to noise ratio, a ratio greater than 4 is desirable, so the ratio of 14.60 indicates an adequate signal and this model can be used to navigate the design space.

The F-value of 18.37 implies that the model is significant. There is only a $1.75 \%$ chance that an Fvalue this large could occur due to noise. The smaller $p$-value indicates the high significance of the corresponding coefficient.

The analyzed results of biomass production by lactobacillus strain (C7) suggested that out of 5 different independent variables, only 3 variables ( $\mathrm{Nacl}$, $\mathrm{pH}$ and inoculum size) were significantly affected the cell dry weight. The $p$-value of these significant variables ranged 0.007 to 0.028 Table 7 .

Interpretation of the data was based on the signs (positive or negative effect on the response) and statistical significance of coefficients $(P<0.05)$. Interactions between two factors could appear as an antagonistic effect (negative coefficient).

The coefficient of determination $\left(\mathrm{R}^{2}\right)$ was 0.99 (which means that $0.99 \%$ of the total variation was explained by the model) by Lactobacillus strain (C7). This indicates a satisfactory representation of the process models and a high determination between the experimental and predicated values for the selected bacteria. By using Design-Expert, the equation obtained for Taguchi design (first order model) of the selected bacteria was as follows:

\footnotetext{
$Y$ Cell dry weight $=+0.9206+0.0194(\mathrm{Nacl})+0.0069$ $(P H)+0.0194$ (Inoculum size) +0.0069 (Temperature) +0.0044 (Incubation period)
}

Where: $\mathrm{Y}$ is the predicated response. 
Table 5. Organic acids in fermentation broth of Lactobacillus brevis C7 by HPLC.

\begin{tabular}{|c|c|c|}
\hline $\mathbf{R F}$ & Compound & Concentration $\mathbf{~ m g} / \mathbf{m L}$ \\
\hline 9.3 & Sorbic acid & 3.12 \\
10.02 & Formic acid & 4.96 \\
10.32 & Citric acid & 5.22 \\
15.0 & Probionic acid & 15.23 \\
18.12 & Butyric acid & 1.25 \\
18.61 & Lactic acid & 12.36 \\
\hline
\end{tabular}

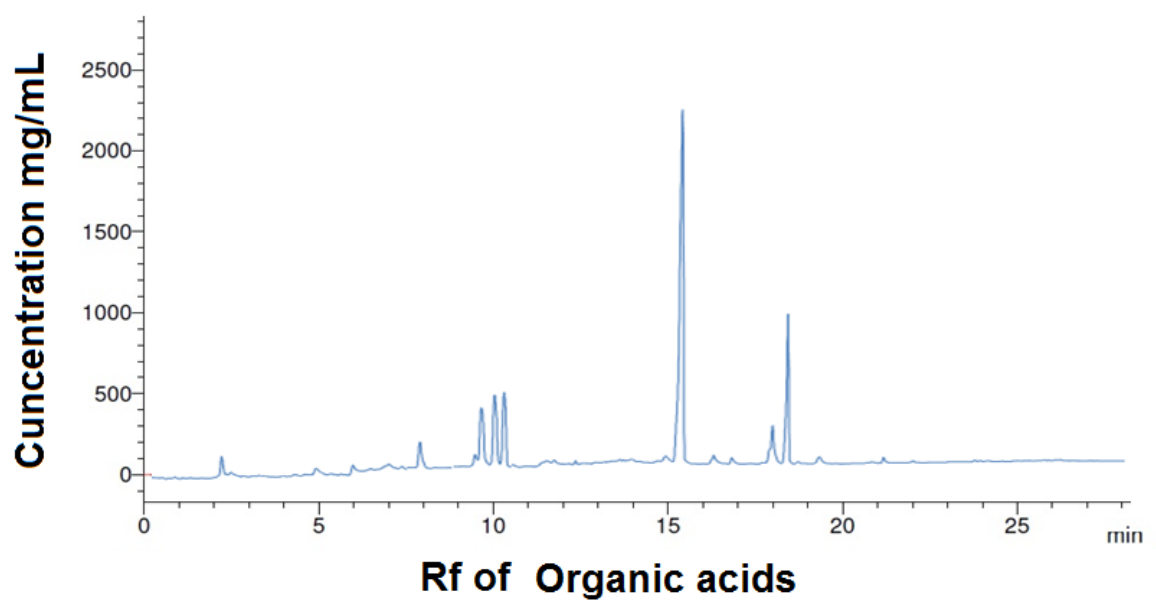

Fig. 5. HPLC Chromatograph chart showing organic acids in fermentation broth of Lactobacillus strain C7 (Lactobacillus brevis). Data are the mean \pm SD of at least three independent experiments

Table 6. Taguchi experimental design matrix and cell dry weight real values of the Lactobacillus brevis (C7).

\begin{tabular}{|c|c|c|c|c|c|c|}
\hline \multirow{2}{*}{$\begin{array}{c}\text { Run } \\
\text { no. }\end{array}$} & \multicolumn{5}{|c|}{ Variables } & $\begin{array}{c}\text { Cell dry weight } \\
\text { (g/L) }\end{array}$ \\
\cline { 2 - 5 } & A & B & C & D & E & \\
\hline 1 & 6.5 & 7 & 5 & 40 & 24 & 0.88 \\
2 & 4 & 5.5 & 7 & 40 & 48 & 0.92 \\
3 & 2 & 7 & 10 & 25 & 48 & 0.87 \\
4 & 4 & 6.5 & 10 & 35 & 24 & 0.91 \\
5 & 0 & 7 & 7 & 35 & 72 & 0.88 \\
6 & 2 & 6.5 & 2 & 40 & 72 & 0.93 \\
7 & 6.5 & 5.5 & 10 & 30 & 72 & 0.90 \\
8 & 2 & 5.5 & 5 & 35 & 96 & 0.93 \\
9 & 2 & 7.5 & 7 & 30 & 24 & 0.91 \\
10 & 4 & 7 & 2 & 30 & 96 & 0.90 \\
11 & 0 & 6.5 & 5 & 30 & 48 & 0.97 \\
12 & 0 & 5.5 & 2 & 25 & 24 & 0.96 \\
13 & 6.5 & 6.5 & 7 & 25 & 96 & 0.90 \\
14 & 0 & 7.5 & 10 & 40 & 96 & 0.95 \\
15 & 4 & 7.5 & 5 & 25 & 72 & 0.98 \\
16 & 6.5 & 7.5 & 2 & 35 & 48 & 0.94 \\
\hline A=Nacl & B=pH & C=Inoculum size & D=Temperature & E=Incubate period \\
\hline
\end{tabular}


Evaluation of Lactobacilli properties and their antibacterial substances by using sweet whey as growth medium against pathogenic bacteria

Table 7. Statistical analysis of variance (ANOVA) OF Taguchi design for cell dry weight by the Lactobacillus brevis strain (C7).

\begin{tabular}{|l|l|l|l|l|}
\hline Source & df & Mean Square & F-value & p-value \\
\hline Model & 15 & 0.0013 & 18.37 & $0.018^{*}$ \\
A-Nacl & 3 & 0.001 & 14.26 & $0.028^{*}$ \\
B-pH & 3 & 0.0029 & 39.17 & $0.007^{*}$ \\
C-Inoculum size & 3 & 0.0014 & 18.6 & $0.019^{*}$ \\
D-Temperature & 3 & 0.0001 & 1.46 & 0.382 \\
E-Incubation period & 3 & 0.0001 & 0.0255 & 0.993 \\
\hline Std. Dev. & 0.0085 & & $R^{2}$ & 0.99 \\
Mean & 0.9206 & Adjusted R & 0.93 \\
C.V. \% & 0.9275 & Predicted R $R^{2}$ & 0.62 \\
& & & Adeq Precision & 14.67 \\
\hline
\end{tabular}

The Predicted $R^{2}$ of 0.62 is not as close to the Adjusted $R^{2}$ of 0.93 as one might normally expect; i.e. the difference is more than 0.2. This may indicate a large block effect or a possible problem with your model and/or data. Things to consider are model reduction, response transformation, outliers, etc. All empirical models should be tested by doing confirmation runs.

Adeq Precision measures the signal to noise ratio. A ratio greater than 4 is desirable. Your ratio of 14.6 indicates an adequate signal. This model can be used to navigate the design space. Data illustrated by Fig. (6) indicated the Actual values related with the predicated values in the same line.

Therefore, the present $\mathrm{R}^{2}$ values hinted that the model is reliable for biomass production in the present study.

So, the significant factors ( $\mathrm{Nacl}, \mathrm{pH}$ and Inoculum size) will be optimized using Central composite design in the next study.

\section{Second design the Central composite design (CCD) and response surface methodology (RSM)}

After selecting the most significant variables influencing cell dry weight by the Lactobacillus strain C7. A Central composite design (CCD) was performed to determine the optimal levels of the selected significant variables and optimum amount of cell dry weight. Results of 20 experiments with different combination of salinity ratio $(A), \mathrm{pH}(B)$ and inoculum size $(C)$ represented in (Table 8 ).

The Lactobacillus strain (C7) was observed that the maximum cell dry weight value $(0.98 \mathrm{~g} / \mathrm{l})$ was achieved at runs number $(1,4,5,6,13$ and 19$)$ in the presence of $\mathrm{Nacl}(5.25 \mathrm{~g} / 100 \mathrm{ml})$ at $\mathrm{PH}(7.75)$ with inoculum size $(7.5 \%)$, were attributable to the lowest cell dry weight that was observed in run number 9.

The best runs which represent the same result of actual and predicted cell dry weight, whereas the runs $(1,4,5,6,13$ and 19$)$ being $0.98 \mathrm{~g} / \mathrm{l}$ for actual and predicted, respectively (Fig. 7).

The statistical significance of the model was checked by F-test and ANOVA for the response surface quadratic model (summarized in (Table 8 ) by the Lactobacillus strain C7. The model F-value of 2.39 implies there is a $9.56 \%$ chance that a F-value this large could occur.

The $p$-value less than 0.0500 indicate model terms are significant. In this case $\mathrm{A}^{2}, \mathrm{C}^{2}$ are significant model terms. The values are greater than 0.1000 indicate the model terms are not significant. The determination coefficient R2 of the model was 0.68 for the Lactobacillus isolate indicated that the model explained $68 \%$ of the total variations and revealed excellent agreement between the experimental results and the predicted values calculated from the model. $R 2= \pm 1$, a straight-line relationship exists between the experimental and predicted cell dry weight.

*Significant at $5 \%$ level $(p<0.05), d f=$ degree of freedom, $p=$ corresponding level of significance, $F=$ corresponding level of significance, Std. Dev $=$ Standard Deviation, C.V.= coefficient of variation and $R^{2}=$ Determination coefficient. Adeq Precision measures the signal to noise ratio. A ratio greater than 4 is desirable. Your ratio of 4.160 indicates an adequate signal. This model can be used to navigate the design space. Therefore, the present $\mathrm{R}^{2}$ values hinted that the model is reliable for biomass production in the present study demonstrated that the relatively lower value of coefficient of variation 
(C.V.) indicates a better precision and higher reliability of the experiment. This indicates that C.V. = $3.00 \%$ for the Lactobacillus strain (C7), of this model is perfect. The $p$-value, less than 0.05 , indicated that lack of fit for the model is significant. The mathematical model of the Lactobacillus strain (C7) describing the relationship between variables $(A, B$ and $C)$ and response $(Y)$ for cell dry weight could be obtained by the following second order polynomial equation:

$Y$ cell dry weight $=+0.9813+0.0012(A)+0.0161(B)$ $+0.0044(C)-0.0025(A B)+0.0025(A C)+0.0100(B C)$ $-0.0208\left(A^{2}\right)-0.0155\left(B^{2}\right)-0.0190\left(C^{2}\right)$

Where: $Y$ is the predicted response.
Three-dimensional response surface and twodimensional contour plots are graphical based on the model equation. These plots used to explain the interaction among variables and determine the optimum level of each factor on cell dry weight. Each figure presents the effect of 3 factors while the other factor was held at optimum level. For $2 D$ and $3 D$ graphs, revealed that the F-value is defined as the ratio of the mean square due to regression to the mean square due to error. The probability value of $\left(A^{2}\right)$ and $\left(C^{2}\right)(p-v a l u e<0.05)$ is the most highly significant variable compared to linear, interaction and other quadratic variables.

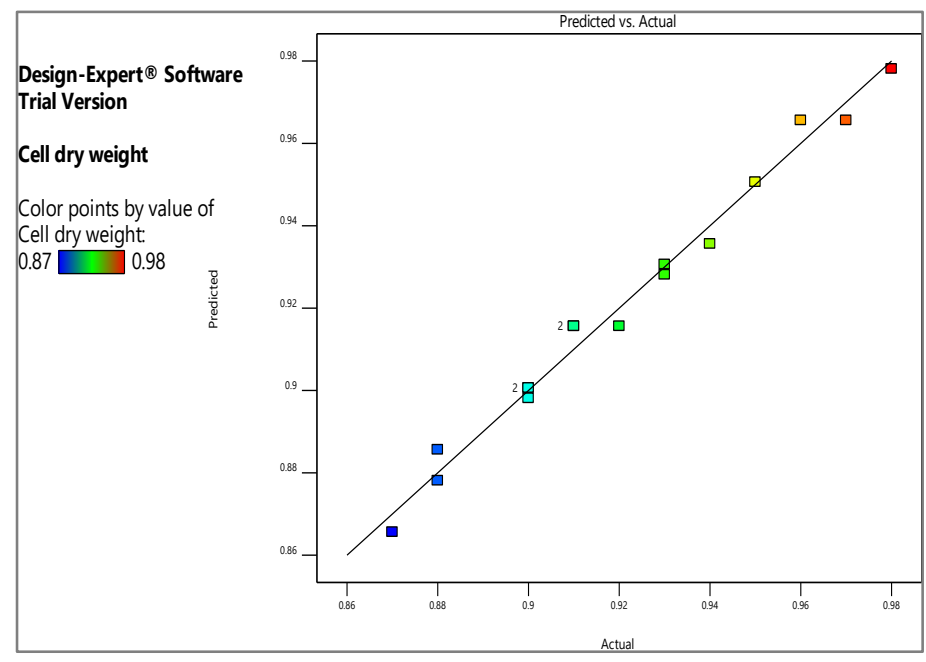

Fig. 6. The actual and predicted values of Taguchi design of the Lactobacillus brevis strain (C7).

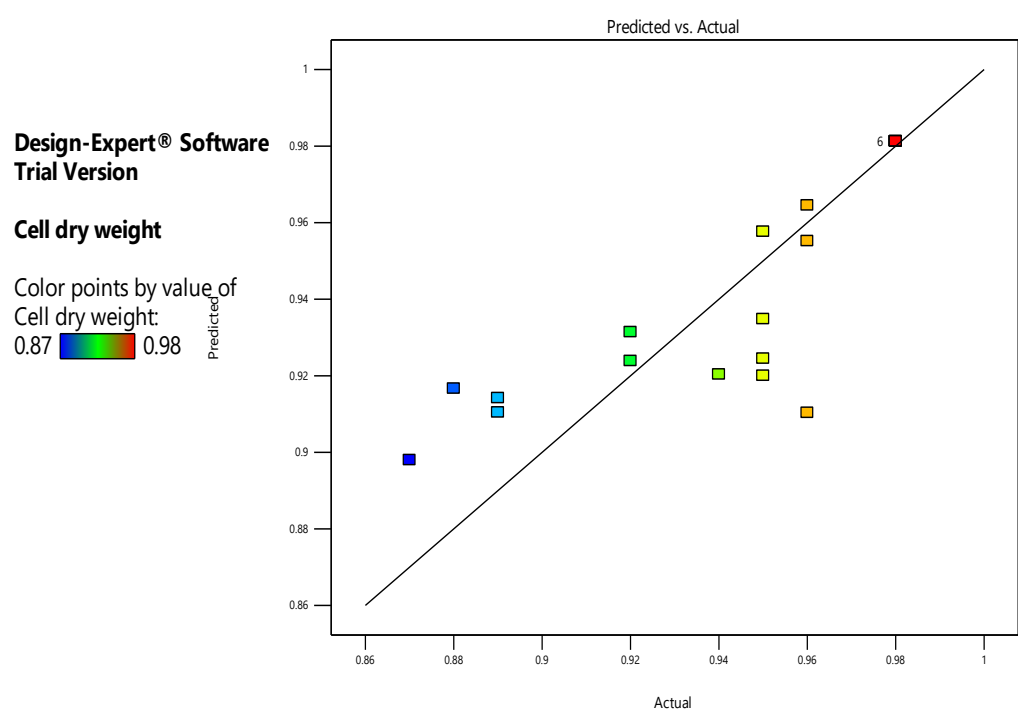

Fig. 7. The actual and predicted values of (CCD) design of the lactobacillus brevis strain (C7). 
Evaluation of Lactobacilli properties and their antibacterial substances by using sweet whey as growth medium against pathogenic bacteria

Table 8. Central composite design matrix of independent variables used in cell dry weight (actual, predicted values) for the Lactobacillus brevis strain (C7).

\begin{tabular}{|c|c|c|c|c|}
\hline \multirow{2}{*}{ Run no. } & \multicolumn{3}{|c|}{ Variables } & \multirow{2}{*}{$\begin{array}{c}\text { Cell dry weight } \\
\text { g/l }\end{array}$} \\
\hline & $\mathbf{A}$ & B & $\mathrm{C}$ & \\
\hline 1 & 5.25 & 7.7 & 7.5 & 0.98 \\
\hline 2 & 6.5 & 7.5 & 5 & 0.88 \\
\hline 3 & 5.25 & 7.7 & 12 & 0.95 \\
\hline 4 & 5.25 & 7.7 & 7.5 & 0.98 \\
\hline 5 & 5.25 & 7.7 & 7.5 & 0.98 \\
\hline 6 & 5.25 & 7.7 & 7.5 & 0.98 \\
\hline 7 & 3 & 7.7 & 7.5 & 0.94 \\
\hline 8 & 5.25 & 7.7 & 3 & 0.95 \\
\hline 9 & 4 & 7.5 & 10 & 0.87 \\
\hline 10 & 6.5 & 8 & 5 & 0.92 \\
\hline 11 & 4 & 8 & 5 & 0.92 \\
\hline 12 & 4 & 8 & 10 & 0.96 \\
\hline 13 & 5.25 & 7.7 & 7.5 & 0.98 \\
\hline 14 & 5.25 & 8.2 & 7.5 & 0.96 \\
\hline 15 & 4 & 7.5 & 5 & 0.89 \\
\hline 16 & 6.5 & 7.5 & 10 & 0.89 \\
\hline 17 & 6.5 & 8 & 10 & 0.95 \\
\hline 18 & 5.25 & 7 & 7.5 & 0.96 \\
\hline 19 & 5.25 & 7.7 & 7.5 & 0.98 \\
\hline 20 & 7 & 7.7 & 7.5 & 0.95 \\
\hline \multirow{2}{*}{ Variable } & & \multirow{2}{*}{ Symbol } & \multicolumn{2}{|c|}{ Real levels } \\
\hline & & & -1 & +1 \\
\hline $\mathrm{Nacl}$ & $\mathrm{g} / 100 \mathrm{ml}$ & A & 4 & 6.5 \\
\hline $\mathrm{pH}$ & $9 / 100 \mathrm{ml}$ & B & 7.5 & 8 \\
\hline Inoculum size & $\%$ & $\mathrm{C}$ & 5 & 10 \\
\hline
\end{tabular}

$-1=$ low level of the variable and $+1=$ high level of the variable

Table 9. Statistical analysis of variance (ANOVA) of (CCD) design for cell dry weight by the Lactobacillus strain (C7).

\begin{tabular}{|c|c|c|c|c|}
\hline Source & df & Mean Square & F-value & p-value \\
\hline Model & 9 & 0.0019 & 2.39 & 0.0956 \\
\hline A-A Nacl & 1 & 0.0000 & 0.0258 & 0.8755 \\
\hline $\mathrm{B}-\mathrm{B} \mathrm{pH}$ & 1 & 0.0035 & 4.42 & 0.0618 \\
\hline $\mathrm{C}-\mathrm{C}$ Incolumn size & 1 & 0.0003 & 0.3288 & 0.5791 \\
\hline$A B$ & 1 & 0.0000 & 0.0624 & 0.8079 \\
\hline$A C$ & 1 & 0.0000 & 0.0624 & 0.8079 \\
\hline $\mathrm{BC}$ & 1 & 0.0008 & 0.9977 & 0.3414 \\
\hline$A^{2}$ & 1 & 0.0062 & 7.78 & $0.0191^{*}$ \\
\hline$B^{2}$ & 1 & 0.0035 & 4.32 & 0.0644 \\
\hline $\mathrm{C}^{2}$ & 1 & 0.0052 & 6.51 & $0.0288^{*}$ \\
\hline $\begin{array}{l}\text { Residual } \\
\text { Lack of Fit } \\
\text { Pure Error } \\
\text { Cor Total }\end{array}$ & $\begin{array}{c}10 \\
5 \\
5 \\
19\end{array}$ & $\begin{array}{l}0.0008 \\
0.0016 \\
0.0000\end{array}$ & & \\
\hline \multicolumn{2}{|c|}{$\begin{array}{c}\text { Std. Dev. } \\
\text { Mean } \\
\text { C.V. } \% \\
\mathbf{R}^{2} \\
\text { Adjusted } \mathbf{R}^{2} \\
\text { Adeq Precision }\end{array}$} & \multicolumn{3}{|c|}{$\begin{array}{c}0.0283 \\
0.9435 \\
3.00 \\
0.6825 \\
0.3968 \\
4.1597 \\
\end{array}$} \\
\hline
\end{tabular}



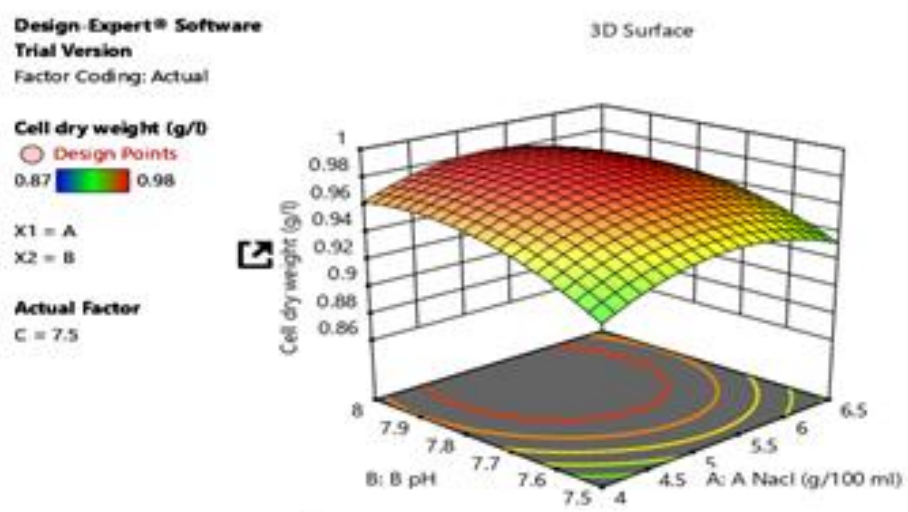

a) Nacl vs. pH

Design Experto Soltware
Trial Vernion
Factor Coding: Actual
Cell dry weight (g/0
Oesign Points
0.87
$X_{1}=$ A
$X_{2}=C$
Actual Factor
$B=7.75$

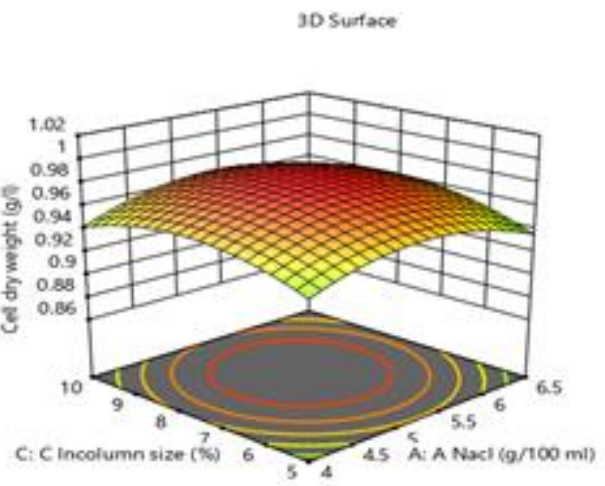

b) Nacl vs. inoculum size

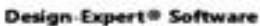

Design - Expert

Factor Coding: Actua

3D surtace

Cell dry weight $(g / \mathrm{D}$

Design Points

$0.87 \mathrm{C}$

$x_{1}=8$

$x_{2}=c$

Actual Factor

$A=5.25$

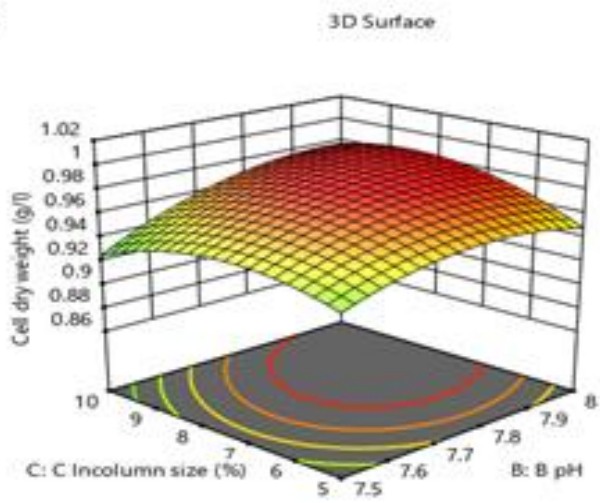

c) $\mathrm{pH}$ vs. inoculum size

Fig. 8. 3-dimensional response surface showing the effect of $\mathrm{Nacl}, \mathrm{pH}$ and Inoculum size on biomass production by the Lactobacillus brevis strain (C7). 

using sweet whey as growth medium against pathogenic bacteria

Similar response data were presented in (Fig. 8). This plot indicates that the optimum conditions for the highest cell dry weight under in media contained $5.25 \mathrm{~g} \mathrm{Nacl} / 100 \mathrm{ml}$ and adjusted $\mathrm{pH}$ to 7.7 then inoculated with $7.5 \%$ of standard inoculum size and incubated at $25^{\circ} \mathrm{C}$ for 72 hours. Data in (Figs. 8 a-c) indicated that the interaction between $\mathrm{Nacl}$ concentrations vs. $\mathrm{pH}$ at $7.5 \%$ of inoculum size (Fig. 8a). The interaction between $\mathrm{Nacl}$ concentrations vs. inoculum size at pH 7.7 (Fig. 8b). In (Fig. 8c) showed the interaction between $\mathrm{pH}$ and inoculum size at $5.25 \mathrm{~g} \mathrm{Nacl} / 100 \mathrm{ml}$. From the previous results, it could be summarized that the production of biomass using two designs Taguchi and CCD for optimized production were not difference in cell dry weight being $0.98 \mathrm{~g} / \mathrm{l}$.

\section{CONCLUSION}

In the present study, 32 LAB isolates were isolated from raw milk and Cottage cheese using the specific De Man, Regosa-Sharp medium and were identified as members of the genus Lactobacillus spp. Sweet whey low-cost by-products proved to be suitable medium for growth and production of antibacterial substances by these isolates. Cell free supernatants (CFS) of these isolates showed potential to antagonize the seven foodborne organisms and pathogens including Gram-positive and Gram-negative bacteria.

These active isolates were good acid producers causing a drop in $\mathrm{pH}$ of supernatants between 3.7 and 4.9 , but activities completely disappeared by neutralization. In addition inhibition due to hydrogen peroxide was excluded because no sensitivity to catalase was detected. Therefore, antibacterial activity could be attributed mainly to organic acids production and to certain extent to bacteriocin compounds which were inactivated by neutralization. CFS of five of these isolates withstanded pasteurization treatment. C7 isolate showed the highest relatively residual activities and was selected, and identified as Lactobacillus brevis. This strain Lactobacillus brevis considered a hetero fermentative to produce $\mathrm{CO}_{2}$ and many organic acids including propionic acid, lactic acid. Citric acid, Formic acid, Sorbic acid and Butyric acid with 15.23, 12.36 5.22, 4.96, 3.12 and $1.25 \mathrm{mg} / \mathrm{mL}$. High mass production of this strain could be achieved by growing at $\mathrm{pH} 7.75$ and $25^{\circ} \mathrm{C}$ at salt concentration of $5.25 \% \mathrm{NaCl}$ and inoculum size $7.5 \%$ with incubation period 72 hours.
Therefore, the growth of Lactobacillus on the sweet whey low-cost by-product will certainly reduce production on the industrial scale. The aforementioned characteristics of this strain together with its strong antibacterial activity against of Gram-positive and Gram-negative pathogens recommended its use as bio-preservative for fermented dairy products which are subjected to harsh heat treatment and could be functional for the production of some cheese which contain relatively high salt concentration.

\section{REFERENCES}

Ali O.A. (2012). Inhibition of uropathogenic Citrobacter adhesion by biosurfactants extracted from vaginal Lactobacillus Acidophilus 10, 59-67.

Axelsson L. (1993). Lactic acid bacteria: classification and Physiology. In: Salminen S, Wright AV, editors. Lactic acid bacteria. Morcel Dekker, pp. 1-64.

Badis A., Laouabdia-Sellami N., Guetarni D., Kihal M. and Ouzrout R. (2005). Caracterisation phenotypique des bacteries lactiques isolees a partir de lait cru de chevre dedeux populations caprines locales" arabia et kabyle". Sciences \& Technologie. C, Biotechnologies, pp. 30-37.

Charlier C., Cretenet M., Even S., Loir Y.L. and Loir Y.L. (2009). Interactions between Staphylococcus aureus and lactic acid bacteria: An old story with new perspectives. International J. of Food Microbiology, 131, 30-39.

De Man J. Rogosa D. and Sharpe M.E. (1960). A medium for the cultivation of lactobacilli. J. of Applied Bacteriology 23, 130-135.

Ghalfi H., Thonart P. and Benkerroum N. (2006). Inhibitory activity of Lactobacillus curvatus CWBI-B28 against Listeria monocytogenes and ST2-verotoxin producing Escherichia coli O157. African J. of Biotechnology 5, 2303-2306.

Guarner F., Khan A.G., Garisch J., Eliakim R., Gangl A. and Thomson A. (2012). World gastroenterology organisation guidelines: probiotics and prebiotics. J. Clin Gasreoenterol 46, 468481.

Hu Chang-Hui, Ren, Li-Quan, Zhou, Y. and Ye, Bang-Ce (2019). Characterization of antimicrobial activity of three Lactobacillus plantarum strains isolated from Chinese traditional dairy food, Food Sci. Nutr. 7, 1997-2005. 
Huang S., Cauty C., Dolivet A., Le Loir Y., Chen X.D. and Schuck P. (2016a). Double use of highly concentrated sweet whey to improve the biomass production and viability of spray dried probiotic bacteria. J. Funct. Foods 23, 453-463.

Ismaili M.A., Guilal J., Hamama A., Saidi B. and Zahar M. (2016). Identification de bactéries lactiques du lait cru de chamelle du sud du Maroc. The Int. J. of Multi -disciplinary Sci., 1, 81-94.

Khedid K., Faid M., Mokhtari A., Soulaymani A. and Zinedine A. (2009). Characterization of lactic acid bacteria isolated from the one humped camel milk produced in Morocco. Microbiological Research, 164, 81- 91.

Lairini S. Beqqali N. Bouslamti R. Belkhou R. and Zerrouq F. (2014). Isolement des bactéries lactiques à partir des produits laitiers traditionnels Marocains et formulation d'un lait fermenté proche du Kéfir. Revue Internationale des Sci. et Technologie. 10, 267-277.

Lleó M.M., Tafi M.C. and Canepari P. (1998). Non culturable enterococcus faecalis cells are metabolically active and capable of resuming active growth. Syst. Appl. Microbio. 21, 333-339.

Mir-hoseini (2004). Study of effect of nisin and producer bacteria of nisin on Listeria monocytogenesand Bacillus cereus. Isfahan: University of Isfahan. 33, 234-342.

Murry A.C., Hinton A. and Morrison H. (2004). Inhibition of growth of Escherichia coli, Salmonella typhimurium and Clostridium perfringens on chicken feed media by Lactobacillus salivarius and Lactobacillus plantarum. Int. J. Poult. Sci. 3, 603-607.
Nisha G. and Krishnamoorthy K. (2018). Inhibitory Activity of Lactobacillus Strains against Food-Borne Pathogens. Int. J. of Current Microbiology and Applied Sci., 7, 445-451.

Osuntoki A. and Korie I. (2010). Antioxidant activity of Whey from milk fermented with lactobacillus species isolated from Nigerian fermented foods. Food Technol Biotechnol 48, 505-511.

Ounine K. Rhoutaisse A. and El Haloui N. (2004). Caractérisation bactériologique du lait cru produit dans les étables de la région du Gharb. Al awamia, pp. 109-110.

Pennacchia C., Ercolini D., Blaiotta G., Pepe O., Mauriello G. and Villani F. (2004). Jour meat science. Barking. 67, 309-317.

Sandra T.S., Janine Barlow, Adele C., Glenn R. and Gibson, Ian R. (2012). In vitro evaluation of the antimicrobial activity of a range of probiotics against pathogens: Evidence for the effects of organic acids. J. Anaerobe. 18, 530-538.

Whittenbury R. (1964). Hydrogen peroxide formation and catalase activity in the lactic acid bacteria. Microbiology, 35, 13-26.

Zalán Z., Hudáček J., Štětina J., Chumchalová J., and Halász A. (2010). Production of organic acids by Lactobacillus strains in three different media. European Food Research \& Technology, 230, 395-404.

Zhao S., Han J., Bie X., Lu Z., Zhang C. and Lv F. (2016). Purification and characterization of plantaricin JLA- 9: A novel bacteriocin against Bacillus spp. produced by Lactobacillus plantarum JLA-9 from Suan- Tsai, a traditional Chinese fermented cabbage. J. of Agric. and Food Chemistry, 64, 2754-2764. 
مجلة اتحاد الجامعات العربية للعلوم الزراعية، جامعة عين شمس، القاهرة، مصر مجلد(28)، عدد(3)، 795-777، 2020

Website: http://ajs.journals.ekb.eg

795

تقييم خصائص العصيات اللبنية (Lactobacilli) وموادها المضادة للبكتيريا بإستخدام الشرش الحلو كبيئة للنمو ضد البكتيريا المسببة للأمراض

[63]

رضوى المغربي نورالدين 1" - محمود محمد زكي 1 - عبدالمحسن أحمد رفعت 1 - أحمد فريد عبدالسلام²

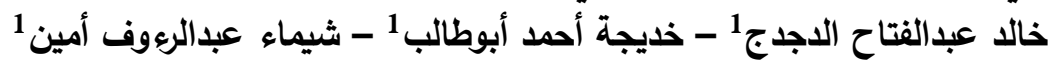

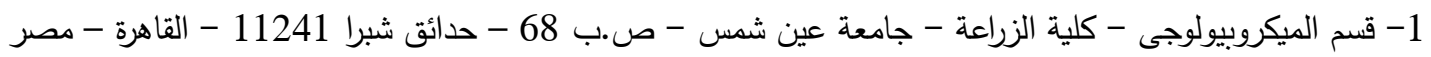

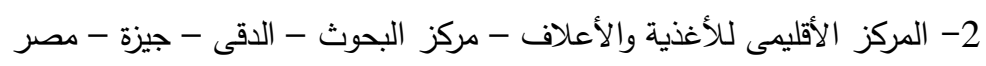

*Corresponding author: chemist.radwa87@yahoo.com

Received 16 July, 2020

Accepted 7 September, 2020

كمضادات لـ 7 انواع من البكتيريا الممرضة كان من

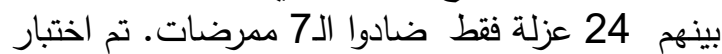

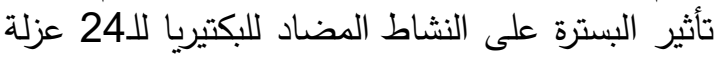

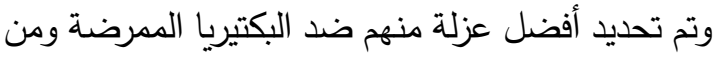

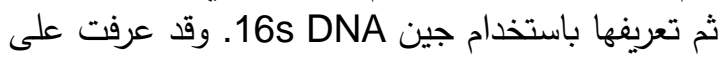

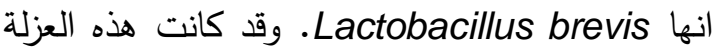
مقاومة لكلوريد الصوديوم حتى تركيز 6.5 \%

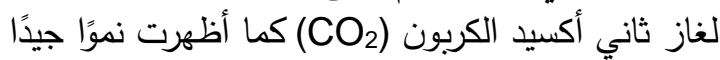

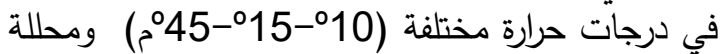

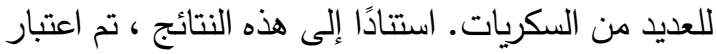

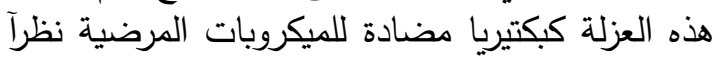

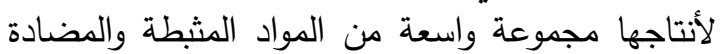

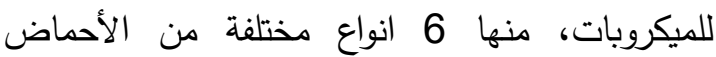
العضوية هم حمض البروبيوتيك، حمض التراعن اللاكتيك. حامض الستريك وحمض الفورميك وحمض السضونيك السوربيك وحمض البيوتريك تم الكثف عنها وتئ وتقديرها من خلال

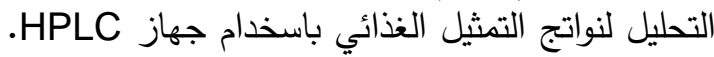

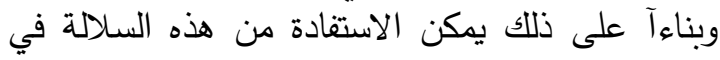

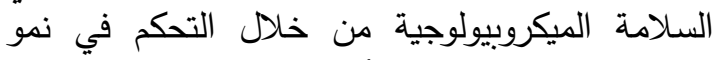

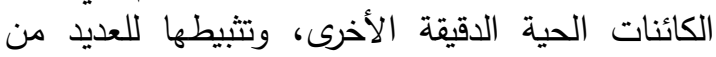

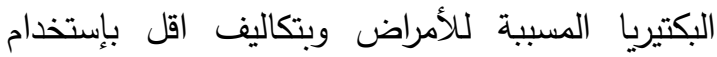

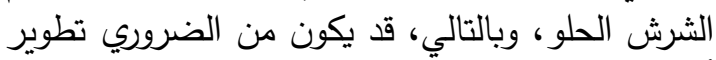

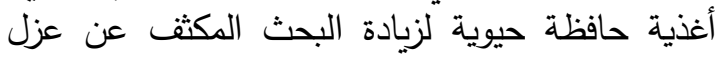
وتوصيف البكتيريا المضادة للميكروبات من منتجات التيات الألبان المحلية وتحسين نموها.

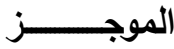

أدى الطلب المتزايد من المستهلكين الذين يبحثون عن منتجات آمنة طبيعية والمخاطر الصحية المحتملة المئل للمنتجات الغذائية المحفوظة كيميائياً والمعالجة كيميائياً

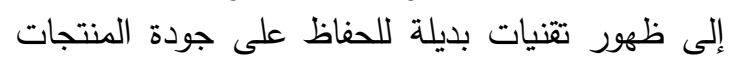

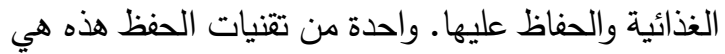

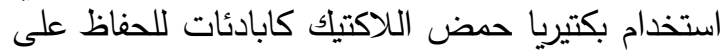

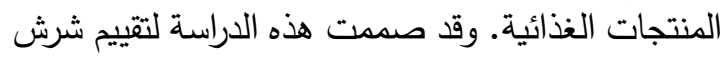
اللبن الحلو ذو التكلفة المنخفضة والذي التئي يعد منتج ثانوي

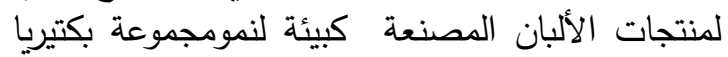

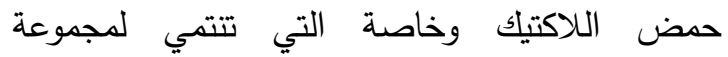

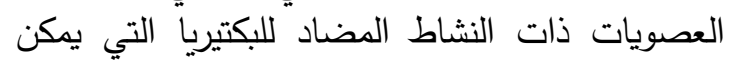
استخدامها في الحفظ الحيوي لمنتجات الألبان التيات التخمرة.

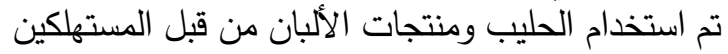

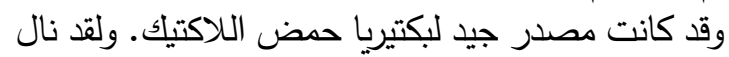

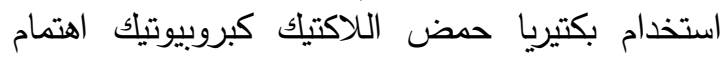

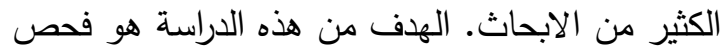

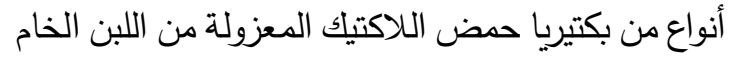
والجبن مع اختبار قدرتها كمضادات للبكتيريا. تعتبر بيئة الفينة

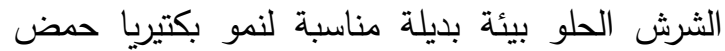
اللاكتيك وانتاجها للمواد المضادة للبكتيريا بدلآ من البيئة

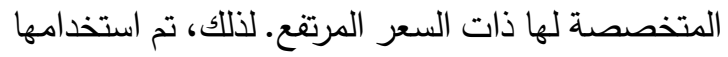

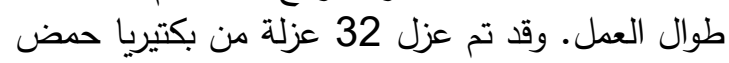
اللاكتيك ومن خلال تعريفها مورفولوجياً وكيميائياً وجد ان جميع العزلات تتنمي الى جنس اللاكتوباسيلس والتي ولتي تندرج تحت مجموعة العصويات ولنئ العن خلال اختبارهم 